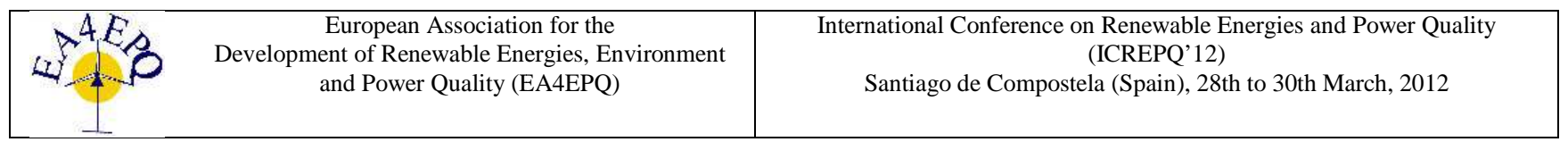

\title{
A Contribution to Isolated and Grid-Connected Photovoltaic Systems under Shadow Conditions
}

\author{
A. F. Cupertino ${ }^{1}$, J. T. de Resende ${ }^{1}$, B. M. Silveira ${ }^{1}$, A. O. R. Vilela ${ }^{1}$, H. A. Pereira ${ }^{1}$ \\ ${ }^{1}$ Department of Electrical Engineering \\ Universidade Federal de Viçosa \\ Campus UFV - Viçosa, Minas Gerais, Brazil, CEP: 36590-000 \\ Phone/Fax number: +55 31 3899-3266
}

E-mails: allan.cupertino@yahoo.com.br, resende@ufv.br, bruno.silveira@ufv.br, afranio_ruas@hotmail.com, heverton.pereira@ufv.br

\begin{abstract}
The power supplied by photovoltaic panel is sensitive to radiation incident on itself. Both isolated and grid connected applications are very important to keep constant output voltage. The load usually works in constant voltage. Variation on radiation levels may lead to not constant output voltage. This work presents the use of a PID controller in a boost converter able to provide constant voltage for an isolated system, even during radiation variation in solar panel. This work also presents a PI controller to a three-phase inverter CC/CA in grid connected system. The controller is designed to inject the whole power produced by the photovoltaic panels on the grid.
\end{abstract}

\section{Key words}

Photovoltaic panel, PID/ PI controller, isolated/ connected system, shadow.

\section{Introduction}

It has been observed a significant increase of interest in renewable energy sources. There are among these sources solar and wind energy [1], [2]. There are some advantages of using these sources. For instance: availability and low environmental impact [3].

Photovoltaic solar energy has several applications, such as electric cars, satellites, communication systems in remote locations, pumping systems and others. The installed capacity has grown exponentially as shown in Fig. 1. In 2010 it reached a value of $39.5 \mathrm{GW}$, and in 2009 alone there was an increase of $16.6 \mathrm{GW}$. According to [4] the installed power in 2015 will be something around 131.3 GW.

The performance of a photovoltaic solar system is mostly dependent on climatic conditions [5]. The incident solar radiation and temperature are factors that significantly contribute to its power generated [6], [7], [8].

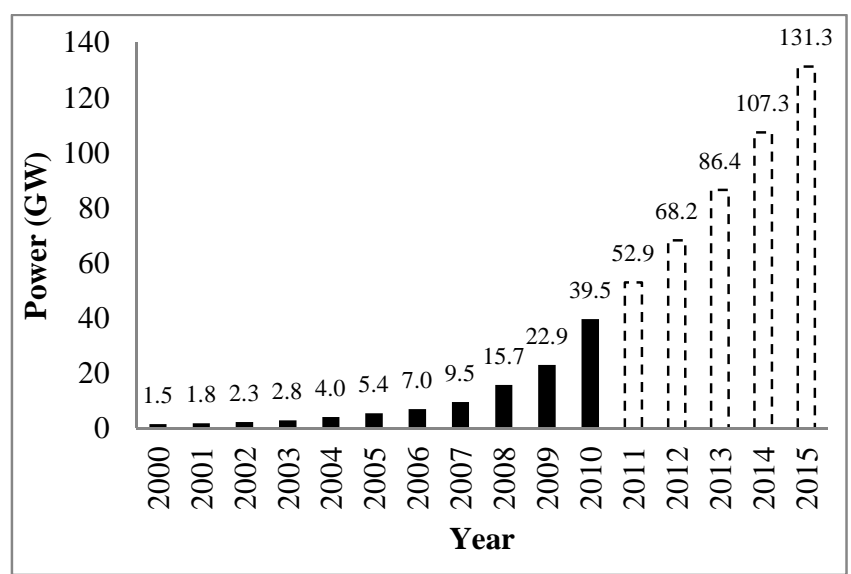

Fig. 1. Growth of the global PV installed power in the world and a forecast until 2015 [4].

The action of shading decreases incident radiation on a solar panel. This provides a significant decrease in power output and affects the supply at the load. These shadings can be caused by clouds, poles, trees and even a panel on the other panel, depending on the position of the sun [5], [9], [10].

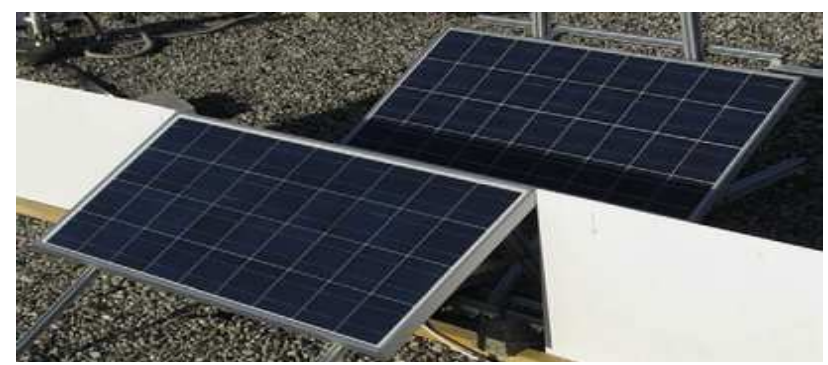

Fig. 2. Diagram illustrating the shading caused solely by the position of the sun in relation to the photovoltaic panels [10].

In an application connected to the grid, the voltage level generated must be as stable as possible due its interaction with a pre-existent system. If this does not occur, it is possible that during a shade time the whole panel looks like a load to the system. A consequence of that would be 
the activation of protection system and the disconnection of it from the main grid [11].

There are in the literature several studies seeking to develop methodologies to improve the performance of photovoltaic systems during shading. In [9] the performance and accuracy of maximum power point tracking (MPPT) techniques under the influence of partial shading are simulated and compared. The reference [12] develops adaptive reconfiguration algorithm to reconfigure connections between solar PV arrays in real time in order to optimize output power.

This paper proposes the design of a controlled Boost converter applied in a solar panel in partial shadow conditions. Besides, it will be proposed the use of a controlled inverter and a LCL filter that allows the connection of the system to the grid.

\section{Methodology}

The model of solar panel used in this work, shown in Fig. 3 , is used by several works in the literature [7]. In such model, a controlled current source represents the generated current due to incident solar radiation. The CC voltage source represents the open circuit voltage of the cell. The losses of a PV cell are represented by $R_{p m}$ and $R_{s m}$, which are the resistance of the pn-junction of the crystals and the resistance of the metal-load contact, respectively.

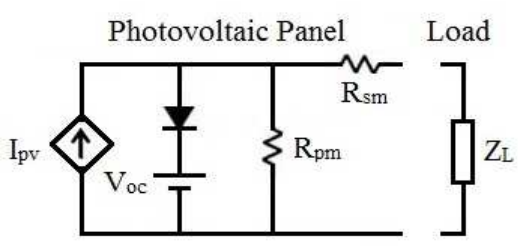

Fig. 3. Electric model for a solar panel.

At first, the methodology used for the isolated system feeding a DC load will be described. The second step will be describing the methodology used for grid-connection application.

\section{A. Isolated application}

The topology of boost converter used is shown in Fig. 4. The model considered the resistance of the semiconductor device in on-state $R_{o n}$, the resistance of the inductor $R_{L}$ and the voltage of diode $V_{D}$. In addition, the load was considered as a resistance in parallel with a current source. The latter represents variations in the power consumed by the load.

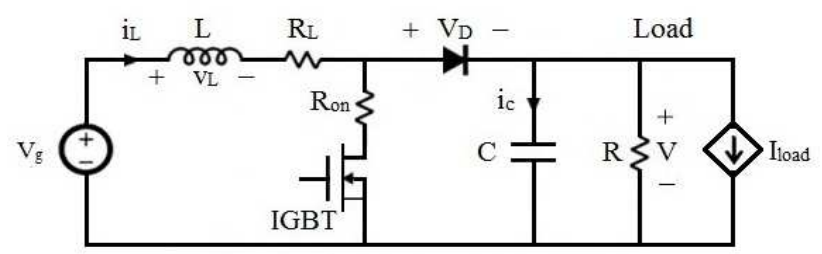

Fig. 4. Topology of boost converter.
State space equations used in the modeling of this component are:

$$
\begin{aligned}
<\dot{X}>= & \left(A_{0}+d \cdot\left(A_{1}-A_{0}\right)\right) \cdot<X>+ \\
& \left.+\left(B_{0}+d \cdot\left(B_{1}-B_{0}\right)\right) \cdot<U>\right)
\end{aligned}
$$

Where:

$$
\begin{aligned}
& A_{1}=\left[\begin{array}{cc}
-\frac{\left(R_{L}+R_{o n}\right)}{L} & 0 \\
0 & -\frac{1}{R C}
\end{array}\right] ; A_{0}=\left[\begin{array}{cc}
-\frac{R_{L}}{L} & -\frac{1}{L} \\
\frac{1}{C} & -\frac{1}{R C}
\end{array}\right] ; \\
& B_{1}=\left[\begin{array}{ccc}
\frac{1}{L} & 0 & 0 \\
0 & 0 & -\frac{1}{C}
\end{array}\right] ; B_{0}=\left[\begin{array}{ccc}
\frac{1}{L} & -\frac{1}{L} & 0 \\
0 & 0 & -\frac{1}{C}
\end{array}\right] ; \\
& \dot{X}=\left[\begin{array}{l}
\frac{d i_{L}}{d t} \\
\frac{d v}{d t}
\end{array}\right] ; X=\left[\begin{array}{l}
i \\
v
\end{array}\right] ; U=\left[\begin{array}{c}
V_{g} \\
V_{D} \\
I_{\text {load }}
\end{array}\right] ; \\
& \text { ‘ }<>\text { represents the average value of the variable. }
\end{aligned}
$$

$d$ is given by equation (2).

$$
d= \begin{cases}1, & \text { on }- \text { state } \\ 0, & \text { off }- \text { state }\end{cases}
$$

The equation (1) is nonlinear because it involves the multiplication of time-varying quantities. Therefore, it is necessary to linearize the model. In this paper a small signal model is used [13]. The first step of this method is generating a small disturbance in steady state and verifying what happens to the system. Then,

$$
\left\{\begin{array}{c}
d=D+\hat{d} \\
<X>=x+\hat{x} \\
<U>=u+\hat{u}
\end{array}\right.
$$

After algebraic manipulations and application of Laplace's transform, result is:

$$
\left[\begin{array}{c}
\hat{\imath} \\
\hat{v}
\end{array}\right]=\left[\begin{array}{llll}
F_{11}(s) & F_{12}(s) & F_{13}(s) & F_{14}(s) \\
F_{21}(s) & F_{22}(s) & F_{23}(s) & F_{24}(s)
\end{array}\right] \cdot\left[\begin{array}{c}
\widehat{V}_{g} \\
0 \\
\hat{l}_{\text {load }} \\
\hat{d}
\end{array}\right]
$$

Therefore:

$$
\hat{v}=G_{v d} \cdot \hat{d}+G_{v g} \cdot \hat{v}_{g}-Z_{\text {out }} \cdot \hat{\imath}_{\text {load }}
$$

Where:

$$
\begin{gathered}
G_{v g}(s)=F_{21}(s)=\left.\frac{\hat{v}(s)}{\hat{v}_{g}(s)}\right|_{\substack{\hat{d}=0 \\
\hat{\imath}_{\text {load }}=0}} \\
Z_{\text {out }}(s)=F_{23}(s)=-\left.\frac{\hat{v}(s)}{\hat{\imath}_{\text {load }}(s)}\right|_{\substack{\hat{v}_{g}=0 \\
\hat{d}=0}}
\end{gathered}
$$




$$
G_{v d}(s)=F_{24}(s)=\left.\frac{\hat{v}(s)}{\hat{d}(s)}\right|_{\substack{\hat{v}_{g}=0 \\ \hat{\imath}_{\text {load }}=0}}
$$

The boost converter proposed in this work is shown in Fig. 5. The transfer function $G_{c}(s)$ represents the PID controller. Fig. 6 presents a block diagram of the small signal model. It was added the sensor gain $H(s)$, the transfer function of compensator $G_{c}(s)$ and the amplitude of PWM modulator $\left(V_{m}\right)$.

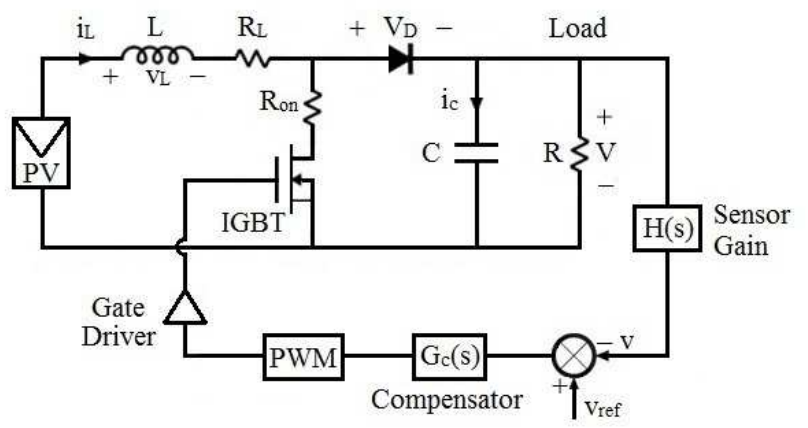

Fig. 5. Controlled Boost converter.

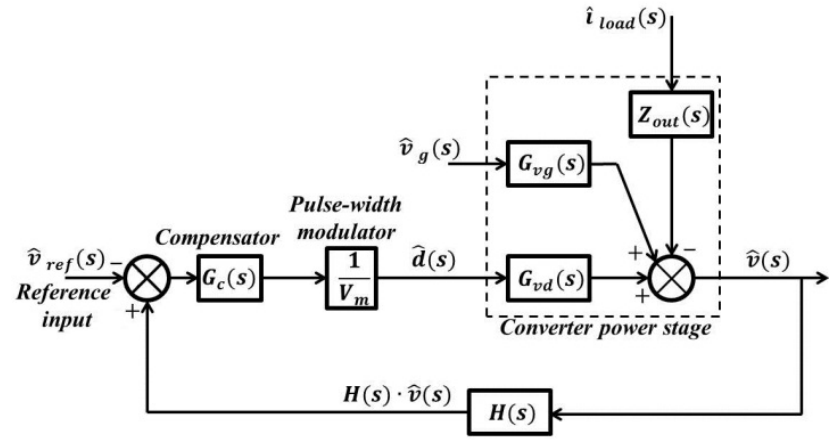

Fig. 6. Diagram of the small signal model for the Fig. 5 [13].

After calculating the transfer function of Fig. 6 and effectuating algebraic manipulations the result is:

$$
\begin{aligned}
\hat{v}(s)=\hat{v}_{\text {ref }}(s) & \cdot \frac{1}{H(s)} \cdot \frac{T(s)}{1+T(s)}+\hat{v}_{g}(s) \cdot \frac{G_{v g}(s)}{1+T(s)} \\
& -\hat{\imath}_{\text {load }} \cdot \frac{Z_{\text {out }}}{1+T(s)}
\end{aligned}
$$

$T(s)$ is called Loop Gain and its expression is:

$$
T(s)=\frac{H(s) \cdot G_{C}(s) \cdot G_{v d}(s)}{V_{m}}
$$

Note that whether magnitude of $T(s)$ becomes large, the dependence of the output voltage gets reduced concerning variations in input voltage and the load. The variations of $v_{\text {ref }}$ will not be considered since the reference voltage used in this work will remain the same. From this, the methodology for design of PID controller presented in [13] was used.

\section{B. Grid-connected application}

The proposed system, shown in Fig. 7, uses a controlled inverter to process the power supplied by photovoltaic panels and to inject it in electric grid. A LCL filter was used for eliminating harmonic distortion produced by the switching.

For the design of LCL filter, the methodology of reference [14] was used. The advantage in using a filter LCL in spite of RL filter is that LCL filter allows more reduction in the higher frequencies, reducing the harmonic of close order to the switching frequency. The resistor $\mathrm{Rd}$ improves the acting of the filter because it reduces the resonance pick of this.

The capacitor of DC bus is designed through methodology of reference [15]. The function of this capacitor is to provide voltage with minimum wavy in the entrance of the inverter so this can operate correctly.

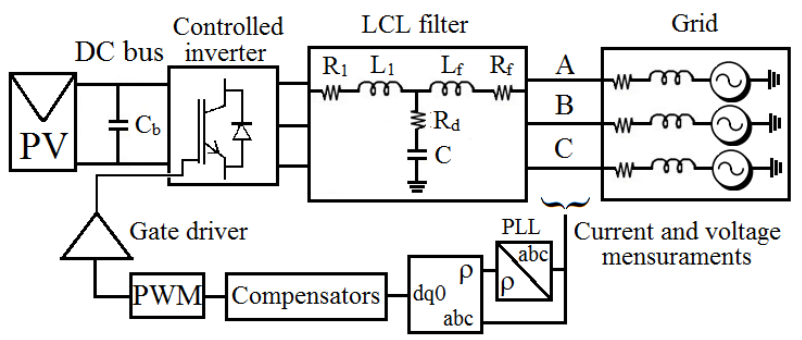

Fig. 7. Solar photovoltaic system connected to electrical grid.

For modeling the system, it will be assumed that in the frequency of grid the LCL filter can be approximate for a $\mathrm{L}$ filter whose inductance is the sum of the inductances $L_{1}$ and $L_{f}$. Equation that governs the system in the notation of space fasor is shown in (11).

$$
\vec{v}=R \cdot \vec{\imath}+L \cdot \frac{d \vec{\imath}}{d t}+j w L \cdot \vec{\imath}+\vec{V}
$$

Where:

$\vec{v}$ is the spacial fasor of inverter exit.

$\vec{V}$ is the spacial fasor of grid voltage. $\vec{\imath}$ is the spacial fasor of filter current. $w$ is the angular frequency of grid.

$L=L f+L 1$.

$R=R f+R 1$.

Extracting the components $d$ and $q$ of equation (11):

$$
\begin{aligned}
& v_{d}=R \cdot i_{d}+L \cdot \frac{d i_{d}}{d t}-w \cdot L \cdot i_{q}+V_{d} \\
& v_{q}=R \cdot i_{q}+L \cdot \frac{d i_{q}}{d t}+w \cdot L \cdot i_{d}+V_{q}
\end{aligned}
$$


The term $V_{q}$ in equation (12) is negligible because the use of a phase-locked loop (PLL) allows eliminating component of quadrature of voltage through determination of the angle of the synchronous system coordinates.

The equations (12) and (13) show that the voltages of axes $d$ and $q$ are coupled by the terms crossed $w \cdot L \cdot i_{d}$ and $w \cdot L \cdot i_{q}$. These terms should be compensated by direct action. The compensation becomes the variables direct axis independent of the variables axis quadrature.

The reference of current of sequence zero $\left(I_{0 \_}\right.$ref $)$is made zero to compensate component that circulates for the system. In the other hand, the reference of the current in the quadrature axis $\left(I_{q_{-} r e f}\right)$ is null in order to annul the reactive power injected on the grid. Finally, the current reference $I_{d \_r e f}$ in the direct axis is calculated in agreement with the power that can be injected in the electric grid (that depends of the climatic conditions) and it is given by equation (14).

$$
I d_{r e f}=\frac{P \cdot \sqrt{2}}{V \cdot \sqrt{3}}
$$

Where:

$P$ is the power that can be injecting on the grid.

$V$ is the RMS phase voltage of the grid.

With the technique of pole allocation it was possible to determine the gain of PI controllers. The voltage signal obtained through a generator of pulses that drive IGBT's of the inverter. The complete system is presented in Fig. 8.

The follow simulations are presented for prove the robustness of the projected control systems.

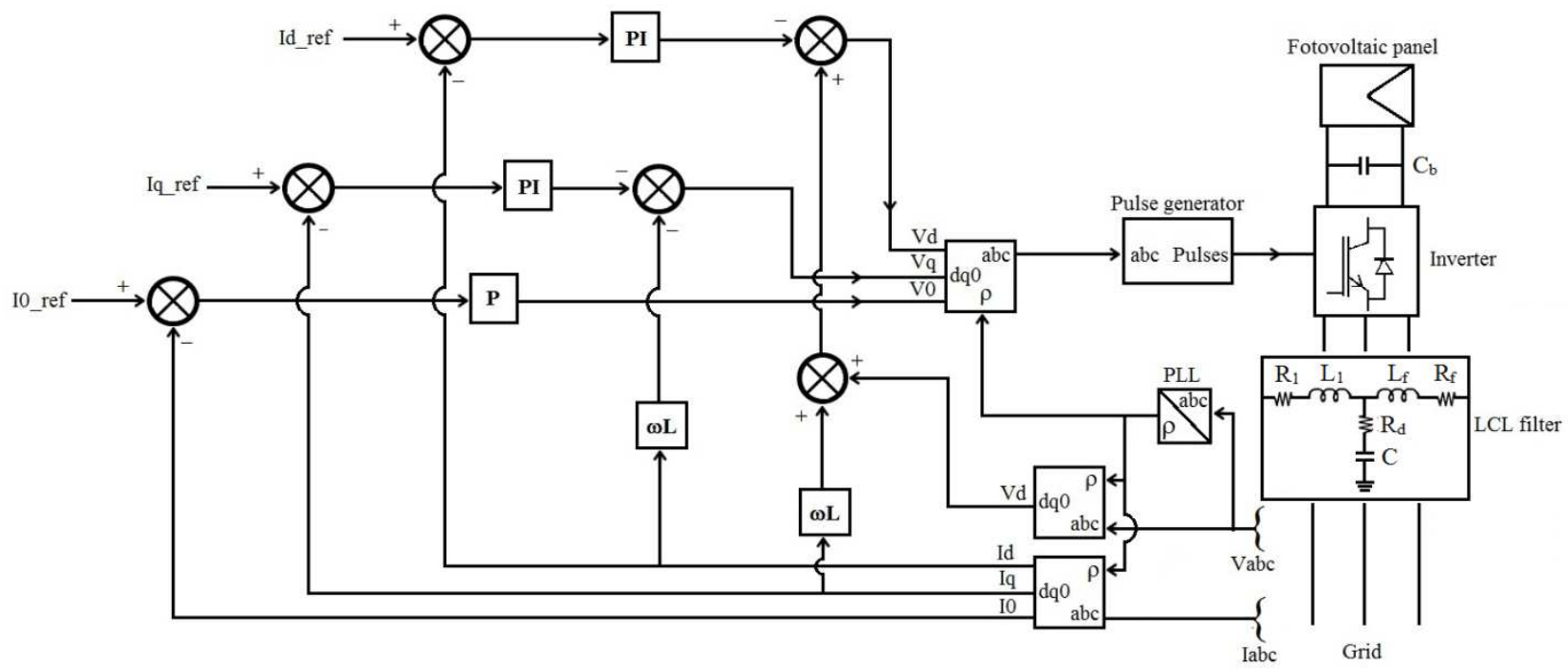

Fig. 8. Complete grid-connected system show control loops.

\section{Results}

\section{A. Isolated application}

A boost converter for application in isolated systems was initially projected. The parameters of this converter are presented in Table I. Table II shows the parameters of solar panel used in this work.

With these parameters it is possible to accomplish PID controller project. The simulation of the system show in Fig. 5 was made in Matlab/Simulink. The PV block represents 3 connected panels in parallel supplying power for a load of constant impedance. In the instant 1 second, a fall was accomplished in the incident radiation (shading) on one of the panels for $100 \mathrm{~W} / \mathrm{m}^{2}(10 \%$ of the reference value).
Table I. - Parameters of boost converter.

\begin{tabular}{|c|c|}
\hline PARAMETER & VALUE \\
\hline $\mathrm{L}$ & $1.5 \mathrm{mH}$ \\
\hline $\mathrm{C}$ & $4.8 \mathrm{mF}$ \\
\hline $\mathrm{D}$ & $60 \%$ \\
\hline $\mathrm{P}$ & $400 \mathrm{~W}$ \\
\hline $\mathrm{f}_{\mathrm{S}}$ & $100 \mathrm{kHz}$ \\
\hline $\mathrm{R}_{\mathrm{L}}$ & $0.01 \Omega$ \\
\hline $\mathrm{R}_{\mathrm{on}}$ & $0.001 \Omega$ \\
\hline $\mathrm{V}$ & $50 \mathrm{~V}$ \\
\hline
\end{tabular}

Table II. - Parameters of PV panel.

\begin{tabular}{|c|c|}
\hline PARAMETER & VALUE \\
\hline $\mathrm{V}_{\mathrm{oc}}$ & $36.9 \mathrm{~V}$ \\
\hline $\mathrm{I}_{\mathrm{sc}}$ & $8.55 \mathrm{~A}$ \\
\hline $\mathrm{R}_{\mathrm{pm}}$ & $55.91 \Omega$ \\
\hline $\mathrm{R}_{\mathrm{sm}}$ & $0.9 \Omega$ \\
\hline $\mathrm{V}_{\mathrm{mpp}}$ & $29.8 \mathrm{~V}$ \\
\hline $\mathrm{I}_{\operatorname{mpp}}$ & $7.89 \mathrm{~A}$ \\
\hline $\mathrm{P}_{\max }$ & $235 \mathrm{~W}$ \\
\hline
\end{tabular}


It is possible to observe in Fig. 9 that the converter, even working out of the nominal condition of operation, got to maintain the voltage in the load in the value of $50 \mathrm{~V}$. This happened because the PID controller calculated a new value of duty cycle, allowing voltage close to the reference. The system also kept supply power almost constant and it can be observed in Fig. 10.

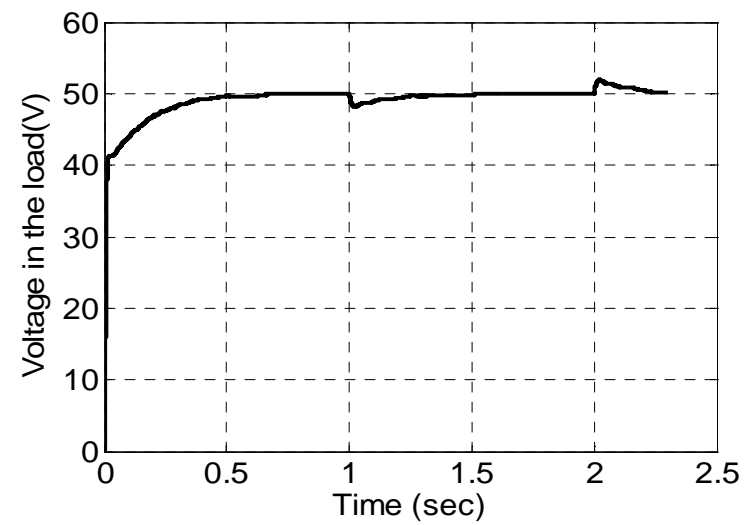

Fig. 9. Voltage in the load for a shading of $10 \%$ in one panel.

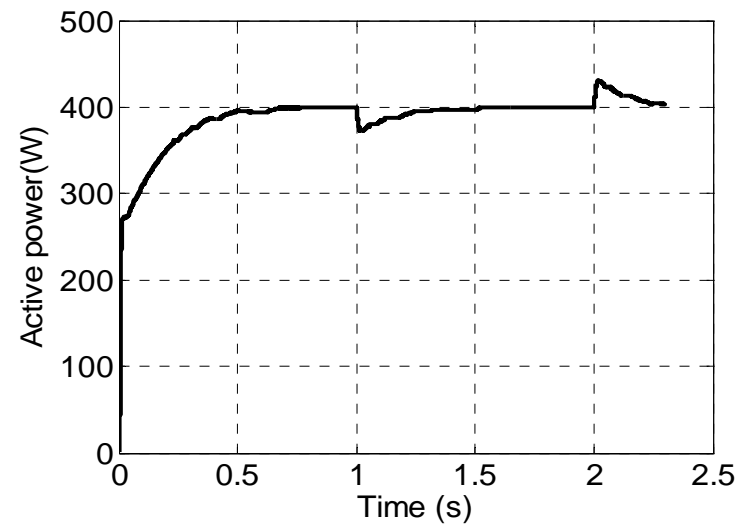

Fig. 10. Active power in the load for a shading of $10 \%$ in one panel.

To show the efficiency of the converter, it was made a simulation in which radiation suffered a fall in ramp. The curve of maximum theoretical power was lifted up assuming that this point is proportional the incident radiation. Besides, the power supplied by the panels and the power in the exit of the converter (through load steps) were measured. The result is shown in Fig. 11.

It is possible to observe that efficiency of the converter was close of to $87 \%$. This value is acceptable for a converter operating at a high switching frequency. Low switching frequencies increase the inductance and capacitance converter value.

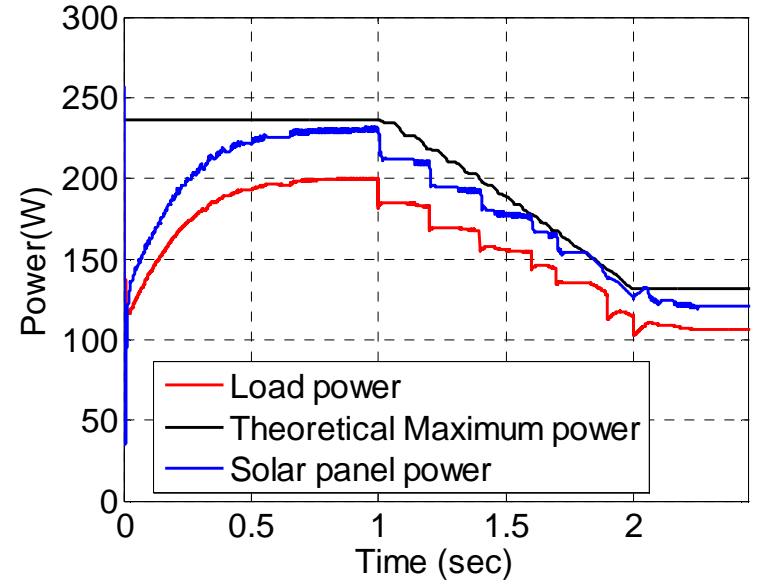

Fig. 11. Power curves for determination of efficiency of converter.

\section{B. Grid-connected application}

In grid-connected application, it was projected a controlled inverter and a LCL filter whose parameters are showed in the Table III and Table IV. From these parameters, the gains of controllers were calculated using the method of pole allocation.

Table III. - Parameters of LCL filter.

\begin{tabular}{|c|c|}
\hline PARAMETER & VALUE \\
\hline $\mathrm{L}_{1}$ & $1.4 \mathrm{mH}$ \\
\hline $\mathrm{C}$ & $66.62 \mu \mathrm{F}$ \\
\hline $\mathrm{L}_{\mathrm{f}}$ & $0.029 \mathrm{mH}$ \\
\hline $\mathrm{R}_{\mathrm{d}}$ & $1.3 \Omega$ \\
\hline
\end{tabular}

Table IV. - Parameters of inverter.

\begin{tabular}{|c|c|}
\hline PARAMETER & VALUE \\
\hline $\mathrm{P}$ & $200 \mathrm{~W}$ \\
\hline $\mathrm{V}$ (phase to phase) & $20 \mathrm{~V}(\mathrm{RMS})$ \\
\hline $\mathrm{f}_{\mathrm{s}}$ & $10 \mathrm{kHz}$ \\
\hline $\mathrm{C}_{\mathrm{b}}$ & $3.3 \mathrm{mF}$ \\
\hline
\end{tabular}

A simulation of the system show in Fig. 8 was performed in Matlab/Simulink. In the instant 2 seconds a fall was accomplished in the incident radiation on the panel of $40 \%$ of the reference value that corresponds to $400 \mathrm{~W} / \mathrm{m}^{2}$.

Fig. 12 shows the voltage and the current injected in the grid. It is possible to observe that the control quickly stabilizes the current. Fig. 13 shows the active and reactive power injected on the grid. In the moment of the shading, the active power injected on the grid has a fall, due to incident radiation decrease.

The active power reduction was caused by decrease in the injected current showed in Fig. 14. The current doesn't have phase change, and the reactive power injected keeps close to zero. 


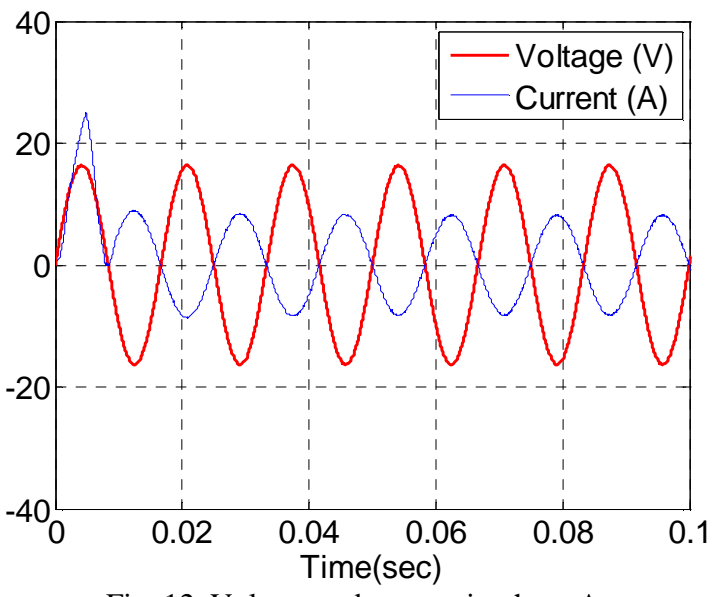

Fig. 12. Voltage and current in phase A.

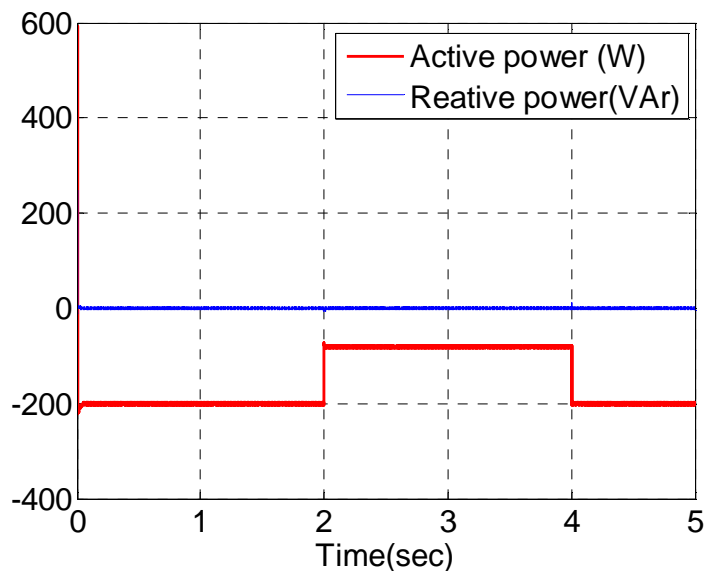

Fig. 13. Active and reactive power injected on the grid.

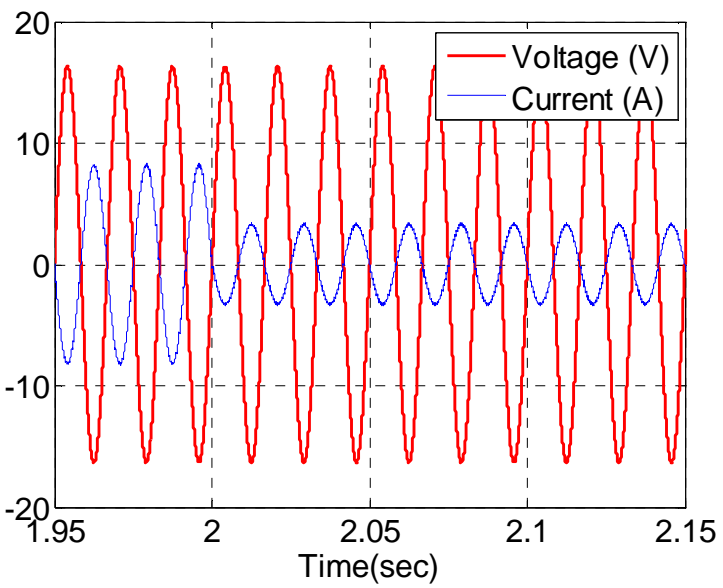

Fig. 14. Voltage and current in phase $\mathrm{A}$ in the moment of shading.

\section{Conclusions}

The objective of this work was to present methodology for improve the performance of PV systems. For isolated applications, a controlled boost converter was projected and allowed to supply with constant voltage a load with yield close to $86 \%$.

For grid-connected applications a controlled inverter was proposed. That allows controlling the injected current on the grid, even during shadow conditions. Currently a prototypal is being built to validate the simulation results.

\section{Acknowledgement}

The authors would like to thank to CNPQ, FAPEMIG and CAPES for their assistance and financial support.

\section{References}

[1] CARRASCO, et al. Power-Electronic Systems for the Grid Integration of Renewable Energy Sources: A Survey. IEEE Transactions on Industrial Electronics, v. 53, August 2006.

[2] BLAABJERG, ; CHEN, ; KJAER,. Power Electronics as Efficient Interface in Dispersed Power Generation Systems. IEEE Transactions on Industrial Electronics, v. 19, SEPTEMBER 2004.

[3] MONGE, B. et al. Multilevel Diode-Clamped Converter for Photovoltaic Generators With Independent Voltage Control of Each Solar Array. IEEE Transactions on Industrial Electronics, v. 55, JULY 2008.

[4] EPIA. European Photovoltaic Industry Association. [S.1.]: [s.n.].

[5] DORADO, E. et al. Influence of the PV modules layout in the power losses of a PV array with shadows. EPE, 2010.

[6] NGUYEN , ; LEHMAN , B. A Reconfigurable Solar Photovoltaic Array Under Shadow Conditions. ECE Department, Northeastern University. Boston.

[7] JI, Y.-H. et al. C-language Based PV Array Simulation Technique Considering Effects of Partial Shading. School of Information and Communication engineering, Sungkyunkwan University. [S.1.].

[8] KARAZHANOV, S. Z. Temperature and doping level dependence of solar cell performace including excitons. Solar Energy and Materials \& Solar Cells, v. 63, n. 2, p. 149-163, Juy 2000.

[9] MASOUM, S.; PADOVAN, ; MASOUM,. Impact of Partial Shading on Voltage- and Current-Based Maximum Power Point Tracking of Solar Modules. [S.1.].

[10] BRECL, K.; TOPIC, M. Self-shading losses of fixed freestanding PV arrays. Renewable Energy, v. 36, n. 11, p. 3211-3216, March 2011.

[11] MASTERS, G. M. Renewable and Efficient Electric Power Systems. New Jersey: Wiley Interscience, 2004.

[12] NGUYEN, D. D. Modeling and reconfiguration of solar photovoltaic arrays under non-uniform shadow conditions. Northeastern University. [S.1.]. 2008.

[13] ERICKSON, R. W.; MAKSIMOVIC', D. Fundamentals of Power Eletronics. $2^{\text {a }}$. ed. New York: Klumer Academic Publishers, 2004.

[14] LISERRE, M.; BLAABJERG, L.; HANSEN, S. Design and control of an LCL-filter based three-phase active rectifier. IEEE, 2001

[15] KAMNARN, U.; KANTHAPHAYAO, Y.; CHUNKAG, V. Three-Phase AC to DC Converter with minimized DC bus Capacitor and fast dynamic response. IEEE, 2007. $<\mathrm{http} / / /$ ieeexplore.ieee.org/xpls/abs_all.jsp?arnumber $=4487$ $772 \& \operatorname{tag}=1>$. Date: 05 dez. 2011. 